\title{
The factor structure of the Edinburgh Postnatal Depression Scale among perinatal high-risk and community samples in London
}

\author{
Alexandra Lautarescu ${ }^{1,2}\left(\right.$ D $\cdot$ Suresh Victor ${ }^{1} \cdot$ Alex Lau-Zhu $^{3,4} \cdot$ Serena J. Counsell ${ }^{1} \cdot$ A. David Edwards ${ }^{1}$. \\ Michael C. Craig ${ }^{2,5}$
}

Received: 2 February 2021 / Accepted: 7 June 2021 / Published online: 10 July 2021

(c) The Author(s) 2021

\begin{abstract}
Timely and accurate detection of perinatal mental health problems is essential for the wellbeing of both mother and child. Growing evidence has suggested that the Edinburgh Postnatal Depression Scale (EPDS) is not a unidimensional measure of perinatal depression, but can be used to screen for anxiety disorders. We aimed to assess the factor structure of the EPDS in 3 different groups of women: $n=266$ pregnant women at high-risk of depression ("Perinatal Stress Study"), $n=471$ pregnant women from a community sample, and $n=637$ early postnatal women from a community sample ("developing Human Connectome Project"). Exploratory factor analysis (40\% of each sample) and confirmatory factor analysis (60\% of each sample) were performed. The relationship between EPDS scores and history of mental health concerns was investigated. Results suggested that a 3-factor model (depression, anxiety, and anhedonia) is the most appropriate across groups. The anxiety subscale (EPDS-3A) emerged consistently and was related to maternal history of anxiety disorders in the prenatal sample $(W=6861, p<0.001)$. EPDS total score was related to history of mental health problems in both the prenatal $(W=12,185$, $p<0.001)$ and postnatal samples $(W=30,044, p<0.001)$. In both high-risk and community samples in the perinatal period, the EPDS appears to consist of depression, anxiety, and anhedonia subscales. A better understanding of the multifactorial structure of the EPDS can inform diagnosis and management of women in the prenatal and postnatal period. Further research is required to validate the EPDS-3A as a screening tool for anxiety.
\end{abstract}

Keywords EPDS $\cdot$ Depression $\cdot$ Anxiety $\cdot$ Perinatal $\cdot$ Factor analysis

Alexandra Lautarescu

Alexandra.Lautarescu@kcl.ac.uk

1 Centre for the Developing Brain, School of Biomedical Engineering and Imaging Sciences, King's College London, Westminster Bridge Road, London SE1 7EH, UK

2 Department of Forensic and Neurodevelopmental Sciences, Institute of Psychiatry, Psychology and Neuroscience, King's College London, London, UK

3 Oxford Institute of Clinical Psychology Training and Research, Medical Sciences Division, University of Oxford, Oxford, UK

4 Division of Psychiatry, Department of Brain Sciences, Imperial College London, London, UK

5 National Female Hormone Clinic, South London and Maudsley National Health Service Foundation Trust, London, UK

\section{Introduction}

Mood and anxiety disorders in the perinatal period affect up to a quarter of women (Howard and Khalifeh 2020). Timely and accurate diagnosis is essential (Kroenke 2020), as early interventions have the greatest potential to improve the wellbeing of mothers and children (Phua et al. 2017; Letourneau et al. 2017). However, as it has been estimated that over half of cases go undetected (National Childbirth Trust 2017; Sudhanthar and Thakur 2019), guidelines have recommended screening and case-finding strategies (National Institute for Health and Care Excellence 2014; Austin et al. 2017; Scottish Intercollegiate Guidelines Network (SIGN), 2012; American College of Obstetricians and Gynecologists 2018).

However, screening strategies to date have focused predominantly on perinatal depression. This is a significant shortcoming, as exposure to prenatal maternal anxiety has detrimental behavioural and cognitive effects on the offspring (van der Zee-van den Berg et al. 2019; O’Donnell 
et al. 2017) and associated changes in early brain development (Lautarescu et al. 2020). Further, prenatal anxiety is associated with an increased risk for severe postnatal depression (Norhayati et al. 2015). A recommendation to expand antenatal screening to include a tool to assess for anxiety may be impractical in the context of antenatal clinics that are already under significant pressure. An alternative would be to adapt our current screening tools to identify potential anxiety disorders.

The most commonly used screening questionnaire for perinatal depression is the 10-item self-rating Edinburgh Postnatal Depression Scale (EPDS). This was originally developed for postnatal depression (Cox et al. 1987), but its use has since been expanded to prenatal populations (Kozinszky and Dudas 2015; Vázquez and Míguez 2019; Smith-Nielsen et al. 2018). A total score of 13 or more is typically considered to indicate depressive symptoms (Cox et al. 1987; Milgrom and Gemmill, 2015), but a recent metaanalysis suggested that a cut-off of 11 or more maximises combined sensitivity and specificity across reference standards (Levis et al. 2020).

Growing evidence from factor analysis studies suggests that the EPDS is not a unidimensional measure of depression and may be a useful tool for screening for perinatal anxiety (Matthey 2008). More specifically, 3 of the EPDS questions, namely items 3 ("I have blamed myself unnecessarily when things went wrong"), 4 ("I have been anxious or worried for no good reason") and 5 ("I have felt scared or panicky for no very good reason"), are suggested to constitute an anxiety subscale, called the EPDS-3A. In perinatal women, the EPDS-3A has been found in studies using the English version of the EPDS (Ross et al 2003; Jomeen and Martin 2007; Matthey 2008; Tuohy and McVey 2008; Cunningham et al. 2015) as well as studies using translated versions of the EPDS such the Chinese (Lau et al. 2010), Spanish (Hartley et al. 2014), Japanese (Kubota et al. 2014), Hebrew (Bina and Harrington 2016) or Danish (Smith-Nielsen et al. 2018) versions. It is important to note that some studies do not find the EPDS-3A as a separate factor (e.g. Coates et al. 2017; Phillips et al. 2009), some report an anxiety factor including other items (e.g. Adouard et al. 2005) and some report that a one-factor model is the best fit for the data (e.g. Lydsdottir et al. 2019).

A growing number of researchers have suggested a separate analysis of the EPDS-3A score to screen for perinatal anxiety (Jomeen and Martin 2005; Swalm et al. 2010; Matthey 2008; Phillips et al. 2009; Tuohy and McVey 2008). High scores on the EPDS-3A have been associated with anxiety disorders (Matthey 2008), being a "worrier" (Swalm et al. 2010) and are more strongly associated with anxiety than depression scores (Loyal et al. 2020). Further, the EPDS-3A has the potential to be particularly helpful in detecting anxiety disorders without comorbid depression, in women who may otherwise not reach the total cut-off score necessary for further action (Matthey 2008; Muzik et al. 2000). A cut-off of 6 or more was validated in a postnatal community sample (Matthey 2008), while a cut-off of 4 or more was validated in a sample of women with unsettled infants (Phillips et al. 2009). However, some researchers have voiced concerns regarding the suitability of the EPDS-3A as a screening measure (Adhikari et al. 2020; van der Zee-van den Berg et al.2019; Matthey and Agostini 2017, Matthey et al. 2013).

Although previous studies have examined the factor structure of the EPDS, the methodology used for exploratory factor analysis (EFA) and confirmatory factor analysis (CFA) has been inconsistent. Most EFA studies have incorrectly used orthogonal rotations, which assume that variables are not correlated (e.g. Swalm et al. 2010; Maroto-Navarro et al. 2005; Mazhari and Nakhaee 2007; Vivilaki et al. 2009; Flom et al. 2018) or principal component analysis, a technique more appropriate for data reduction (e.g. Brouwers et al. 2001; Adouard et al. 2005; Zhong et al. 2014; Agampodi and Agampodi 2013; Töreki et al. 2013; Lau et al. 2010; Montazeri et al. 2007; Chabrol and Teissedre 2004; Matthey 2008). Other studies have used varying methods including polychoric correlation matrices (Lydsdottir et al. 2019), or Pearson correlation matrices with maximum likelihood extraction (MLE, Kubota et al. 2014, 2018; Phillips et al. 2009; Stasik-O'Brien et al. 2019; Coates et al. 2017), ordinary least squares (Chiu et al. 2017) or principal axis factoring (Tuohy and McVey 2008; Pop et al. 1992). CFA studies have used either MLE (Zhong et al. 2014; Flom et al. 2018; Hartley et al. 2014; Kozinsky and Dudas 2015) or weighted least squares methods (Jomeen and Martin 2007; Kwan et al. 2015; Lydsdottir et al. 2019; King 2012; Gutierrez-Zotes et al. 2018; Martin and Redshaw 2018).

The variability in methodology may explain differences in results reported in the literature.

Other methodological limitations in previous studies include small sample sizes, treating the EPDS as an interval rather than ordinal scale, not reporting cross-loadings, not accounting for non-normally distributed data, not reporting the frequency of responses per each individual item, and performing CFA on the same sample on which EFA was done. Further, most studies have focused on postpartum women, with only two UK-based studies investigating the factor structure of the EPDS antenatally (Jomeen and Martin 2005, $n=101$; Jomeen and Martin 2007, $n=148$ ).

In this study, we aim to overcome some of the methodological shortcomings of previous research and assess, both pre- and postnatal, the factor structure of the EPDS in several subsamples, including self-identified high-risk women and community samples. As a past history of anxiety is a risk factor for perinatal anxiety (Leach et al. 2017; Field 2018), a secondary aim of our study was to assess whether the EPDS-3A is associated with maternal history of anxiety disorders. 


\section{Methods}

\section{Participants}

Participants were recruited between March 2015 and March 2020 as part of the developing Human Connectome Project (dHCP, community sample) and the Perinatal Stress Study (high-risk sample). Ethical approval was obtained from the Riverside NHS Research Ethics Committee in the UK (14/ LO/1169 and 18/LO/0786).

The dHCP is a large-scale neuroimaging project, with eligibility criteria including pregnant women (aged 16 years or older), with a gestational age of 20-42 weeks, and newborn infants aged 24-44 weeks. The Perinatal Stress Study included pregnant women (any trimester) who self-identified as experiencing low mood during pregnancy (Supplement).

\section{Measures}

All participants were asked to complete the English version of the EPDS. Total scores were calculated with cut-offs set at 11 or more and at 13 or more. EPDS-3A scores were calculated with cut-offs set at 4 or more and 6 or more.

For the Perinatal Stress Study, women completed the EPDS online, alongside a short demographics questionnaire (maternal age, gestational age, and GP details). Eligible pregnant women (total EPDS 13 or more, BMI $<30$, no contraventions for MRI) were invited to take part in the dHCP (Supplement).

For the dHCP sample, women were asked to complete the EPDS at the time of their visit to St Thomas' Hospital in London for an MRI scan (prenatally and/or postnatally). Participants also completed a questionnaire pack which included demographics, medical history, and mental health history. Participant history of mental health concerns (coded as binary yes/no) was determined based on a combination of multiple sources: maternal self-report (in the questionnaire pack), maternity notes, and mental health records from South London and Maudsley NHS Foundation Trust (Supplement). There are no measures of current depression or anxiety symptomatology other than the EPDS in this study.

\section{Statistical analysis}

Data analysis was performed using R ( $\mathrm{R}$ core team 2018). Throughout the manuscript, " $<$ " is used to signify "less than" and " $>$ " is used to signify "greater than." Each dataset was divided randomly into two subsets: $40 \%$ for EFA and $60 \%$ for CFA. Listwise deletion was used for handling missing data, and only questionnaires with full data were included in the analysis (McNeish 2017). To evaluate the internal consistency of the instrument, Cronbach's alpha $(\alpha)$ was calculated (acceptable value above 0.70 ). We also calculated McDonald's omega ( $\omega$ ) (Hayes and Coutts 2020), as it has been suggested that $\alpha$ is only informative in restrictive settings (Raykov 2004). Raincloud plots were used for visualisation (Allen et al. 2019). Raincloud plots combine splithalf violins (showing the probability density of the data), boxplots (showing the median and interquartile range), and raw data points jittered for improved visibility.

To ensure data were suitable for factor analysis, we calculated the Kaiser-Meyer-Olkin measure of sampling adequacy (acceptable limit of $>0.5$ ) and the Bartlett test of sphericity $(p<0.05$ indicating that the correlations between items are sufficiently large). To detect multicollinearity, we calculated the determinant of the correlation matrix (acceptable value above 0.00001) (Watkins 2018; Jackson et al. 2009; Dziuban and Shirkey 1974).

In subsamples where the frequency of positive responses on item 10 (self-harm) was small, factor analysis was performed on only 9 items, to avoid calculation of potentially negative eigenvalues that would yield non-positive definite matrices (Wothke 1993, as per Chiu et al. 2017; Flom et al. 2018).

\section{EFA}

EFA was conducted on $40 \%$ of the sample. The number of factors for EFA was determined using the conventional Kaiser criteria (eigenvalues above 1), a scree plot, and parallel analysis using Minimum Rank Factor Analysis (MRFA, Shapiro and Berge 2002). MRFA was chosen due to its putative superiority in the identification of the number of factors for ordinal data and performance relative to methods such as Horn's parallel analysis or those based on principal axis factoring (Baglin 2014). As the variables are ordinal, we used polychoric correlations to correct for bias (Holgado-Tello et al. 2010). However, given that the majority of analyses reported to date have treated the EPDS as an interval scale, we also repeated our analysis using a Pearson correlation matrix (Supplement).

The EFA was conducted using MLE with non-orthogonal oblique (oblimin) rotation, as the variables are expected to be correlated (Jomeen and Martin 2005). All loadings of 0.3 or more (including cross-loadings) were included. We applied a cut-off of 0.3 (Howard 2016; Martin and Thompson 1999, 2000; Martin et al. 2004) to generate a more complete psychological interpretation of data (Jomeen and Martin 2005), while a coefficient of 0.5 or more was used to indicate substantial factor loadings. A factor solution was considered meaningful if it explained at least $50 \%$ of variance (Streiner 1994).

An additional EFA was conducted on all 10 items using the whole sample $(n=1190)$, to determine whether there was a common factor structure for women across the 
perinatal period. This included all high-risk participants and one timepoint (randomly selected) for each participant in the community sample.

\section{CFA}

CFA was conducted on the remaining $60 \%$ of the data using weighted least squares mean and variance (WLSMV), which uses polychoric correlations and robust corrections to account for ordinal and nonnormally distributed data (e.g. Lydsdottir et al. 2019; Albuquerque et al. 2017; Martin and Redshaw 2018). As much of the previous literature has used MLE, we also performed CFA using this method (results reported in Supplement).

To test the model fit, we used chi-square statistics, the comparative fit index (CFI, Bentler 1990), and TuckerLewis index (TLI, Tucker and Lewis 1973), with values above 0.95 indicating a good fit (Hu and Bentler 1999) and the Root Mean Square Error of Approximation (RMSEA, Schumacker and Lomax 2010), with values under 0.05 indicating adequate fit (Schumacker and Lomax 2010). Goodness of fit was also considered based on the clearest factor structure (i.e. items loading highly on only one factor, and few cross-loadings), plausibility, and interpretability.

In addition to the models suggested by the EFA, a number of models chosen to reflect the wide variety of solutions from the literature were also examined using CFA: 1-factor model (Cox et al. 1987; Lydsdottir et al. 2019); bifactorial model containing depression and anxiety (Phillips et al. 2009; Matthey 2008); bifactorial model containing depression and anhedonia (Zhong et al. 2014); a 3-factor model containing depression, anxiety, and self-harm (Brouwers et al. 2001); and three 3-factor models containing anhedonia, anxiety, and depression (Lau et al. 2010; Kubota et al. 2014; Tuohy and McVey 2008).

\section{Maternal history of mental health concerns}

To account for ordinal non-normally distributed data, the relationship between EPDS scores and history of mental health concerns was assessed using Wilcoxon rank sum tests, and effect sizes were calculated using Vargha and Delaney's A (vd.a, Vargha and Delaney 2000, see Supplement). As the EPDS only asks about symptoms over the last 7 days, for longitudinal cases (i.e. where more than one EPDS was completed prenatally or postnatally), the highest score was selected for this analysis (see Supplement).

\section{Results}

\section{Descriptive statistics}

In total, 1374 EPDS questionnaires (Table 1) were available for factor analysis ( $n=266$ high-risk sample, $n=1108$ community sample). EPDS total scores in the community sample were lower both prenatally $(5.10 \pm 4.33 ; 3.89 \pm 4.11)$ and postnatally $(5.56 \pm 4.38,6.54 \pm 3.78)$ than in the high-risk prenatal sample $(15.52 \pm 5.25)$. The distribution of scores for item 10 ("The thought of harming myself has occurred to me") was markedly different between the groups, with the community sample answering "Never" in $96.17 \%$ and $96.86 \%$ of the cases (prenatal and postnatal), while this was the case for only $66.16 \%$ of the high-risk sample (Table S2). In the community postnatal sample, the EPDS total score was higher in mothers of babies born extremely preterm (i.e. under 28 weeks), with a mean EPDS total score of $10.13 \pm 5.36$, than in mothers of babies born at term (i.e. over 37 weeks), with a mean EPDS total score of $5.22 \pm 4.12$ (see Supplement). As per the methodology described above, the factor analysis was performed on 10 items in the high-risk sample, and 9 items in the community sample.

\section{Factor analysis}

\section{Reliability}

The Cronbach's $\alpha$ internal reliability coefficients for the EPDS were good for (a) the 10-item questionnaire for the prenatal high-risk sample 0.85 (95\% CI 0.82-0.87), (b) the 9-item questionnaire for the prenatal community sample 0.87 (95\% CI 0.85-0.89) and (c) the postnatal community sample 0.85 (95\% CI 0.83-0.87). Values were similar for McDonald's $\omega$ (Supplement).

\section{EFA}

EFA was conducted on $40 \%$ of each sample $(n=106$ prenatal high-risk, $n=188$ prenatal community, $n=255$ postnatal community). All criteria for factor analysis were met (Table S3). Both 2- and 3-factor models were examined for all samples (Table 2).

In all 3 samples, the 3-factor EFA revealed distinct factors for anhedonia, anxiety, and depression (Table 2), while the 2-factor structure differed between the groups (i.e. anhedonia and depression in the high-risk sample, anxiety and depression in the postnatal community sample, and no clear solution in the prenatal community sample). All factors were positively correlated in all samples (Supplement). The models were similar for the EFA performed with a Pearson correlation matrix (Table S4). The EFA conducted on the 
Table 1 Descriptive statistics

\begin{tabular}{|c|c|c|c|c|c|}
\hline \multirow[b]{2}{*}{ Measures } & \multirow{2}{*}{$\begin{array}{l}\text { High-risk (Perinatal Stress) } \\
\text { Prenatal online }\end{array}$} & \multicolumn{4}{|c|}{ Community (dHCP) } \\
\hline & & $\begin{array}{l}\text { Prenatal } \\
\text { Visit } 1\end{array}$ & $\begin{array}{l}\text { Prenatal } \\
\text { Visit } 2\end{array}$ & $\begin{array}{l}\text { Postnatal } \\
\text { Visit } 1\end{array}$ & $\begin{array}{l}\text { Postnatal } \\
\text { Visit } 2\end{array}$ \\
\hline $\mathrm{N}$ & 266 & $473 *$ & 28 & $640 *$ & 24 \\
\hline \multicolumn{6}{|l|}{ EPDS total score } \\
\hline Mean (SD) & $15.52(5.25)$ & $5.10(4.33)$ & $3.89(4.11)$ & $5.56(4.38)$ & $6.54(3.78)$ \\
\hline Range & $0-28$ & $0-24$ & $0-16$ & $0-28$ & $1-16$ \\
\hline n 11 or more & 223 & 56 & 2 & 75 & 3 \\
\hline n 13 or more & 191 & 32 & 2 & 48 & 1 \\
\hline \multicolumn{6}{|l|}{ EPDS-3A score } \\
\hline $\operatorname{Mean}(\mathrm{SD})$ & $6.17(1.91)$ & $2.72(1.97)$ & $1.93(1.84)$ & $2.71(1.98)$ & $3.43(1.97)$ \\
\hline Range & $0-9$ & $0-9$ & $0-6$ & $0-8$ & $0-7$ \\
\hline n 4 or more & 246 & 151 & 4 & 210 & 12 \\
\hline n 6 or more & 176 & 42 & 2 & 64 & 4 \\
\hline \multicolumn{6}{|l|}{ Maternal age at enrolment (years) } \\
\hline Mean (SD) & $30.52(5.67)$ & $33.79(4.22)$ & $32.75(4.52)$ & $33.81(4.82)$ & $32.96(4.53)$ \\
\hline Range & $18-43$ & $20-46$ & $23-39$ & $17-52$ & $23-41$ \\
\hline $\mathrm{n}$ adolescent mothers ( $<20$ years) & 7 & 0 & 0 & 3 & 0 \\
\hline Missing values ( $n$ ) & 13 & 0 & 0 & 2 & 0 \\
\hline \multicolumn{6}{|l|}{ Gestational age at EPDS (w) } \\
\hline Mean (SD) & $21.72(8.06)$ & $29.65(4.22)$ & $32.51(3.34)$ & $40.00(3.64)$ & $41.57(1.42)$ \\
\hline Range & $4-40$ & $20.86-40.29$ & $26.71-37.43$ & $26.71-45.14$ & $38.43-44.00$ \\
\hline Missing values ( $n$ ) & 7 & 11 & 2 & 6 & 1 \\
\hline Maternal ethnicity & N/A & & & & \\
\hline White British & & 231 & 14 & 261 & 10 \\
\hline White Other & & 132 & 10 & 155 & 4 \\
\hline Black/Black British & & 17 & 0 & 93 & 8 \\
\hline Asian/Asian British & & 49 & 3 & 67 & 0 \\
\hline Mixed ethnic group & & 16 & 1 & 24 & 1 \\
\hline Other & & 10 & 0 & 26 & 1 \\
\hline Missing values $(n)$ & & 18 & 0 & 14 & 0 \\
\hline History of MH & N/A & 148 & 12 & 167 & 5 \\
\hline Ever been treated for $\mathrm{MH}$ & N/A & 90 & 7 & 86 & 2 \\
\hline Ever been under psych^^ & N/A & 22 & 3 & 26 & 0 \\
\hline Ever hospitalised for $\mathrm{MH}^{\wedge}$ & N/A & 3 & 0 & 4 & 0 \\
\hline Self-reported $^{\wedge}$ & N/A & 48 & 4 & 53 & 2 \\
\hline History of depression & N/A & 80 & 6 & 104 & 3 \\
\hline History of anxiety & N/A & 58 & 5 & 51 & 0 \\
\hline Maternal age at leaving formal education & N/A & & & & \\
\hline Mean (SD) & & $23.3(3.81)$ & $24.88(4.99)$ & $23.24(4.51)$ & $23.58(4.88)$ \\
\hline Missing values $(n)$ & & 13 & 3 & 34 & 5 \\
\hline Maternal BMI at enrolment & N/A & & & & \\
\hline Mean (SD) & & $22.68(2.89)$ & $22.3(2.54)$ & $24.38(4.62)$ & $26.25(5.77)$ \\
\hline Missing values $(n)$ & & 17 & 0 & 84 & 1 \\
\hline Maternal smoking $(n)$ & N/A & & & & \\
\hline No & & 432 & 28 & 568 & 21 \\
\hline No, stopped & & 18 & 0 & 31 & 3 \\
\hline Yes & & 5 & 0 & 16 & 0 \\
\hline Missing values & & 18 & 0 & 25 & 0 \\
\hline
\end{tabular}


Table 1 (continued)

\begin{tabular}{|c|c|c|c|c|c|}
\hline \multirow[b]{2}{*}{ Measures } & \multirow{2}{*}{$\begin{array}{l}\text { High-risk (Perinatal Stress) } \\
\text { Prenatal online }\end{array}$} & \multicolumn{4}{|c|}{ Community (dHCP) } \\
\hline & & $\begin{array}{l}\text { Prenatal } \\
\text { Visit } 1\end{array}$ & $\begin{array}{l}\text { Prenatal } \\
\text { Visit } 2\end{array}$ & $\begin{array}{l}\text { Postnatal } \\
\text { Visit } 1\end{array}$ & $\begin{array}{l}\text { Postnatal } \\
\text { Visit } 2\end{array}$ \\
\hline Maternal alcohol consumption $(n)$ & N/A & & & & \\
\hline No & & 384 & 24 & 542 & 2 \\
\hline Yes & & 63 & 4 & 54 & 21 \\
\hline Missing values & & 26 & 0 & 44 & 1 \\
\hline
\end{tabular}

$w$ weeks, $M H$ (poor) mental health, psych psychiatric services, $B M I$ body mass index, $S D$ standard deviation; self-reported=do you have a history of ADHD, bipolar disorder, depression, autism, or schizophrenia; smoking and drinking were measured using the questions "Does the mother currently smoke/drink alcohol".

*Data for all individual questions were available for $n=471$ (prenatal visit 1) and $n=637$ (postnatal visit 1 ), which is the data included in the factor analysis after listwise deletion).

^questions were only asked if answer to "Ever been treated..." was yes.

whole sample ( $n=1190)$ revealed a 2 -factor solution including depression (items $1,2,6,7,8,9)$ and anxiety (items $3,4,5)$ and a 3 -factor solution including anhedonia (items 1,2 ), anxiety (items 3, 4, 5) and depression (items 8, 9) (Table S6).

\section{CFA}

CFA was conducted on $60 \%$ of the sample $(n=160$ prenatal high-risk, $n=283$ prenatal community, $n=382$ postnatal community). Across all groups, the model with the poorest fit was the unifactorial model (chi-square $p$ values $<0.001$, smallest CFI and TLI values, RMSEA poor fit, largest SRMSR values), followed by Zhong et al. (2014) 2-factor model of anhedonia and depression (Table 3). This was supported by the results of the MLE analysis (Table S5).

Across all groups, the model with the best fit was the 3 -factor model including anhedonia (items 1,2), anxiety (items 3, 4, 5), and depression (items 7, 8, 9 and 10 where included in the analysis). This was the 3 -factor model obtained through the EFA on the prenatal high-risk sample, as well as Tuohy and McVey's (2008) and Kubota et al. (2014) models. Lau et al. (2010) 3-factor model was also a good fit (similar to models above, but including item 6 in the depression factor).

Table 2 EFA using polychoric correlation matrices

\begin{tabular}{|c|c|c|c|c|c|c|c|c|c|c|c|c|c|c|c|}
\hline & \multicolumn{5}{|c|}{ Prenatal high-risk } & \multicolumn{5}{|c|}{ Prenatal community } & \multicolumn{5}{|c|}{ Postnatal community } \\
\hline & \multicolumn{2}{|c|}{ 2-factor } & \multicolumn{3}{|c|}{ 3-factor } & \multicolumn{2}{|c|}{ 2-factor } & \multicolumn{3}{|c|}{ 3-factor } & \multicolumn{2}{|c|}{ 2-factor } & \multicolumn{3}{|c|}{ 3-factor } \\
\hline & $\mathrm{D}$ & $\mathrm{AH}$ & $\mathrm{D}$ & $\mathrm{AX}$ & $\mathrm{AH}$ & $\mathrm{D}$ & $\mathrm{AH}$ & $\mathrm{D}$ & $\mathrm{AX}$ & $\mathrm{AH}$ & $\mathrm{D}$ & $\mathrm{AX}$ & $\mathrm{D}$ & $\mathrm{AX}$ & $\mathrm{AH}$ \\
\hline $\begin{array}{l}\text { Variance accounted for } \\
\text { by model }\end{array}$ & $51 \%$ & & $56 \%$ & & & $63 \%$ & & $61 \%$ & & & $57 \%$ & & $58 \%$ & & \\
\hline $\begin{array}{l}\text { Variance accounted for } \\
\text { by each factor }\end{array}$ & $35 \%$ & $16 \%$ & $25 \%$ & $16 \%$ & $15 \%$ & $27 \%$ & $32 \%$ & $26 \%$ & $18 \%$ & $16 \%$ & $34 \%$ & $23 \%$ & $18 \%$ & $23 \%$ & $17 \%$ \\
\hline 1 Able to laugh & & 0.53 & & & 0.55 & & 0.87 & & & 0.96 & 0.93 & & & & 0.74 \\
\hline 2 Look forward & & 1.00 & & & 0.95 & & 1.04 & 0.61 & & 0.59 & 0.78 & & & & 0.88 \\
\hline 3 Blame self & 0.54 & & & 0.74 & & 0.64 & & & 0.61 & & & 0.62 & & 0.59 & \\
\hline 4 Anxious/worried & 0.35 & & & 0.76 & & 0.93 & & & 0.85 & & & 0.81 & & 0.85 & \\
\hline 5 Scared/panicky & 0.54 & & & 0.58 & & 0.59 & & & 0.45 & & & 0.84 & & 0.85 & \\
\hline 6 Overwhelmed & 0.67 & & 0.51 & & & 0.48 & 0.36 & & 0.40 & 0.32 & 0.46 & 0.40 & & 0.46 & 0.36 \\
\hline 7 Difficulty sleep & 0.83 & & 0.67 & & & 0.35 & 0.62 & 0.95 & & & 0.62 & & 0.45 & & \\
\hline $8 \mathrm{Sad}$ or miserable & 0.68 & 0.33 & 0.69 & & 0.36 & 0.33 & 0.59 & 0.84 & & & 0.72 & & 0.60 & & \\
\hline 9 Unhappy/crying & 0.74 & & 0.83 & & & 0.59 & & 0.54 & 0.38 & & 0.67 & & 0.98 & & \\
\hline 10 Self-harm & 0.80 & & 0.75 & & & -- & - & - & - & - & - & - & - & - & - \\
\hline
\end{tabular}

$D$ depression, $A H$ anhedonia, $A X$ anxiety.

*substantial factor loadings ( 0.5 or more) in bold.

For full list of questions, see Supplement. 
Table 3 CFA using WLSMV

\begin{tabular}{|c|c|c|c|c|c|c|c|c|}
\hline \multirow[t]{2}{*}{ Model tested } & \multirow[t]{2}{*}{ Sample } & \multicolumn{7}{|c|}{ Fit indices } \\
\hline & & $X^{2}$ & $P^{*}$ & $\mathrm{df}$ & $\mathrm{CFI}$ & TLI & $\begin{array}{l}\text { RMSEA } \\
\text { (LO90, HI90) }\end{array}$ & SRMSR \\
\hline \multicolumn{9}{|l|}{ EFA 3 factors } \\
\hline $\mathrm{AH}(1,2), \mathrm{AX}(3,4,5), \mathrm{D}(7-10)$ & High risk $\mathrm{A}$ & 36.87 & 0.045 & 24 & 0.986 & 0.979 & $0.058(0.009-0.094)$ & 0.053 \\
\hline $\mathrm{AH}(1), \mathrm{AX}(3,4,5), \mathrm{D}(7-8)$ & Community A & $\wedge$ & $\wedge$ & $\wedge$ & $\wedge$ & $\wedge$ & $\wedge$ & $\wedge$ \\
\hline $\mathrm{AH}(1,2), \mathrm{AX}(3,4,5), \mathrm{D}(8,9)$ & Community $\mathrm{P}$ & 20.73 & 0.036 & 11 & 0.995 & 0.991 & $0.048(0.012-0.080)$ & 0.032 \\
\hline \multicolumn{9}{|l|}{ EFA 2 factors } \\
\hline $\mathrm{AH}(1,2), \mathrm{D}(3,5-10)$ & High risk A & 39.59 & 0.043 & 26 & 0.984 & 0.978 & $0.057(0.011-0.092)$ & 0.054 \\
\hline $\mathrm{AH}(1,2,7,8), \mathrm{D}(3,4,5,9)$ & Community A & 63.21 & $<0.001$ & 19 & 0.968 & 0.953 & $0.091(0.067-0.116)$ & .0 .059 \\
\hline $\mathrm{D}(1,2,7-9), \mathrm{AX}(3,4,5)$ & Community P & 61.93 & $<0.001$ & 19 & 0.982 & 0.973 & $0.077(0.056-0.099)$ & 0.049 \\
\hline \multirow[t]{3}{*}{ One factor } & High risk A & 141.94 & $<0.001$ & 45 & 0.897 & 0.867 & $0.139(0.115-0.163)$ & 0.093 \\
\hline & Community A & 75.17 & $<0.001$ & 27 & 0.987 & 0.983 & $0.080(0.059-0.101)$ & 0.062 \\
\hline & Community $\mathrm{P}$ & 198.5 & $<0.001$ & 27 & 0.936 & 0.915 & $0.129(0.113-0.146)$ & 0.077 \\
\hline \multicolumn{9}{|l|}{ Phillips 2 factors } \\
\hline $\mathrm{D}(1,2,6-10), \mathrm{AX}(3,4,5)$, same as EFA & High risk $\mathrm{A}$ & - & - & - & - & - & - & - \\
\hline $\mathrm{D}(1,2,6-9), \mathrm{AX}(3,4,5)$ & Community A & 42.56 & 0.021 & 26 & 0.996 & 0.994 & $0.048(0.018-0.072)$ & 0.045 \\
\hline $\mathrm{D}(1,2,6-9), \mathrm{AX}(3,4,5)$ & Community P & 82.58 & $<0.001$ & 26 & 0.975 & 0.966 & $0.076(0.058-0.094)$ & 0.049 \\
\hline \multicolumn{9}{|l|}{ Zhong 2 factors } \\
\hline $\mathrm{AH}(1,2), \mathrm{D}(3-10)$ & High risk A & 121.66 & $<0.001$ & 34 & 0.915 & 0.888 & $0.127(0.103-0.152)$ & 0.085 \\
\hline $\mathrm{AH}(1,2), \mathrm{D}(3-9)$ & Community A & 69.06 & 0.001 & 26 & 0.989 & 0.984 & $0.077(0.055-0.099)$ & 0.057 \\
\hline $\mathrm{AH}(1,2), \mathrm{D}(3-9)$ & Community P & 160.6 & $<0.001$ & 26 & 0.942 & 0.919 & $0.117(0.100-0.134)$ & 0.066 \\
\hline \multicolumn{9}{|l|}{ Brouwers $2-3$ factors } \\
\hline $\mathrm{D}(1,2,8), \mathrm{AX}(3,4,5), \mathrm{SH}(10)$ & High risk $\mathrm{A}$ & $\wedge$ & $\wedge$ & $\wedge$ & $\wedge$ & $\wedge$ & $\wedge$ & $\wedge$ \\
\hline $\mathrm{D}(1,2,8), \mathrm{AX}(3,4,5)$ & Community A & 12.43 & 0.133 & 8 & 0.997 & 0.994 & $0.044(0.000-0.090)$ & 0.042 \\
\hline $\mathrm{D}(1,2,8), \mathrm{AX}(3,4,5)$ & Community $\mathrm{P}$ & 33.56 & $<0.001$ & 8 & 0.982 & 0.966 & $0.092(0.061-0.125)$ & 0.051 \\
\hline \multicolumn{9}{|l|}{ Lau 3 factors } \\
\hline $\mathrm{AH}(1,2), \mathrm{AX}(3,4,5), \mathrm{D}(6-10)$ & High risk A & 51.76 & 0.015 & 32 & 0.981 & 0.973 & $0.062(0.028-0.092)$ & 0.058 \\
\hline $\mathrm{AH}(1,2), \mathrm{AX}(3,4,5), \mathrm{D}(6-9)$ & Community A & 36.07 & 0.054 & 24 & 0.997 & 0.995 & $0.042(0.000-0.069)$ & 0.038 \\
\hline $\mathrm{AH}(1,2), \mathrm{AX}(3,4,5), \mathrm{D}(6-9)$ & Community $\mathrm{P}$ & 41.73 & 0.014 & 24 & 0.992 & 0.988 & $0.044(0.020-0.066)$ & 0.035 \\
\hline \multicolumn{9}{|l|}{ Tuohy 3 factors } \\
\hline $\mathrm{AH}(1,2), \mathrm{AX}(3,4,5), \mathrm{D}(7-10)$, same as EFA & High risk $\mathrm{A}$ & - & - & - & - & - & - & - \\
\hline $\mathrm{AH}(1,2), \mathrm{AX}(3,4,5), \mathrm{D}(7-9)$ & Community A & 26.63 & 0.064 & 17 & 0.997 & 0.995 & $0.045(0.000-0.076)$ & 0.039 \\
\hline $\mathrm{AH}(1,2), \mathrm{AX}(3,4,5), \mathrm{D}(7-9)$ & Community $\mathrm{P}$ & 27.14 & 0.056 & 17 & 0.996 & 0.993 & $0.040(0.000-0.066)$ & 0.033 \\
\hline \multicolumn{9}{|l|}{ Kubota 3 factors } \\
\hline $\mathrm{AH}(1,2), \mathrm{AX}(3,4,5), \mathrm{D}(7-9)$ & High risk A & 30.21 & 0.025 & 17 & 0.984 & 0.974 & $0.070(0.025-0.110)$ & 0.050 \\
\hline $\mathrm{AH}(1,2), \mathrm{AX}(3,4,5), \mathrm{D}(7-9)$ Tuohy & Community A & - & - & - & - & - & - & - \\
\hline $\mathrm{AH}(1,2), \mathrm{AX}(3,4,5), \mathrm{D}(7-9)$ Tuohy & Community $\mathrm{P}$ & - & - & - & - & - & - & - \\
\hline
\end{tabular}

*is sensitive to sample size, and can be significant for large samples, ${ }^{\wedge}$ model is not identified, $A$ antenatal/prenatal, $P$ postnatal, $D$ depression, $A X$ anxiety, $A H$ anhedonia, $S H$ self-harm, SRMSR Standardised Root Mean Square Residual. <less than.

\section{EPDS and history of mental health (community sample)}

On average, the highest prenatal EPDS total score was higher in those with a history of mental health conditions ( $n=148, M=8.81, \mathrm{SD}=6.16)$ than in those without a history $(n=325, M=3.88, \mathrm{SD}=3.18), W=12,185$, $p<0.001$, vd. $\mathrm{a}=0.253$ (large effect size). This was also the case in the postnatal sample, where the highest EPDS total score was higher in those with a history of mental health conditions ( $n=167, M=7.25, \mathrm{SD}=5.43)$ than in those without a history $(n=473, M=5.03, \mathrm{SD}=3.80)$, with $W=30,044, p<0.001$, vd.a $=0.382$ (small effect size) (Fig. 1) (Supplement). 
Fig. 1 Raincloud plots showing distribution of highest prenatal and postnatal EPDS scores in women with and without a history of mental health conditions. For each group, jittered raw data are shown on the left; boxplots with median and interquartile range are shown in the middle; and density plots are shown on the right

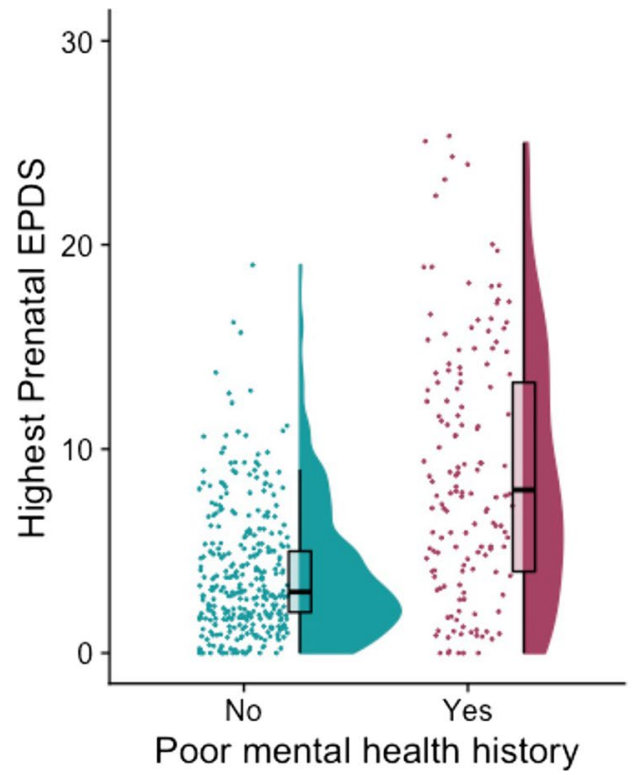

\section{EPDS-3A}

The percentage of women with high EPDS-3A scores but EPDS total scores under threshold varied substantially based on the applied cut-offs (Table S7). For example, when using the EPDS-3A cut-off validated in a community sample (i.e. 6 or more, Matthey 2008) and the EPDS total cutoff recommended by a recent meta-analysis (i.e. 11 or more, Levis et al. 2020), the percentage of women that may have anxiety symptoms but not score high enough on the EPDS total to warrant further assessment ranged between 1.90 and $3.38 \%$. However, when using the EPDS-3A cut-off validated in a sample of women with unsettled infants (i.e. 4 or more,

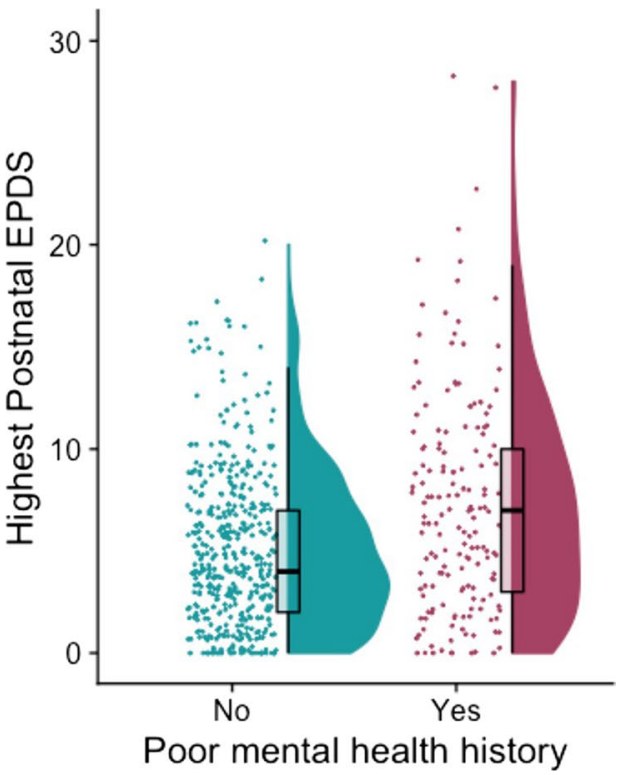

Fig. 2 Raincloud plots showing distribution of the highest prenatal and postnatal EPDS$3 \mathrm{~A}$ scores in women with and without a history of anxiety disorders. For each group, jittered raw data are shown on the left; boxplots with median and interquartile range are shown in the middle; and density plots are shown on the right
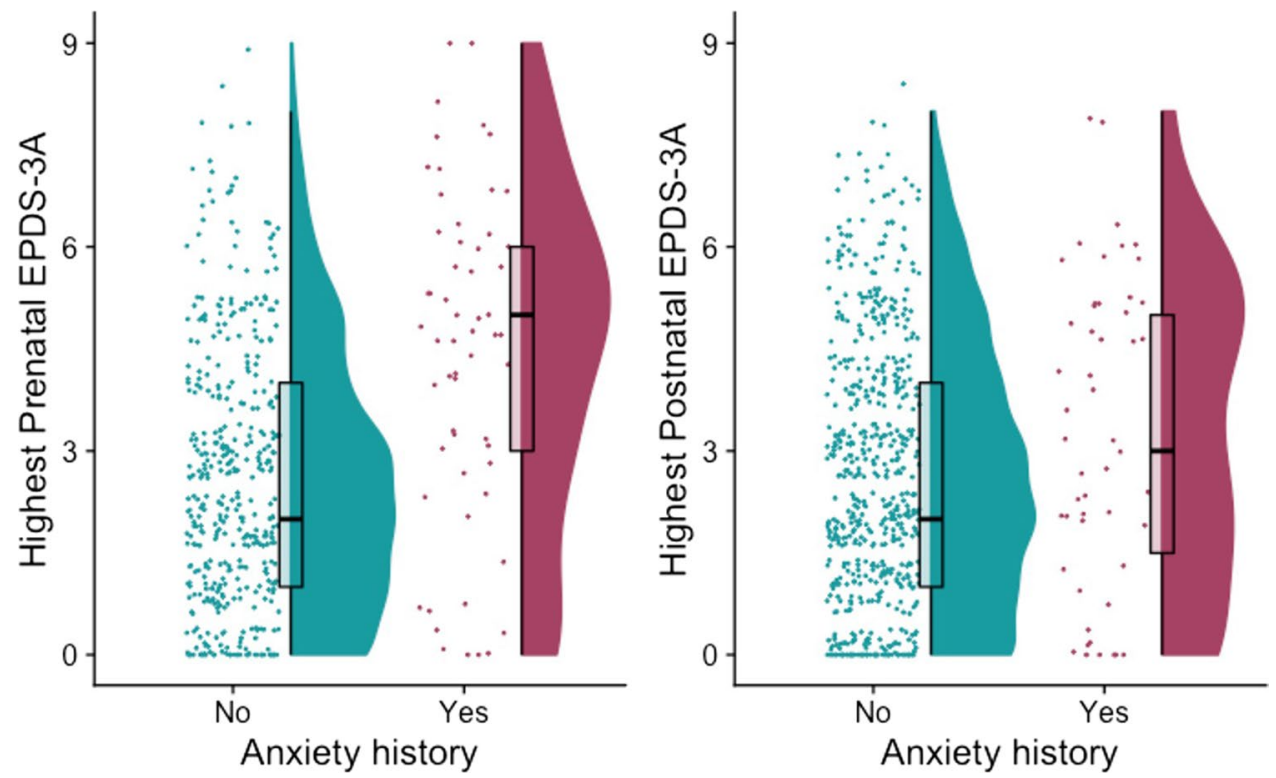

Phillips et al. 2009) and the total EPDS original validated cut-off of 13 or more (Cox et al. 1987), these numbers rose to a range of $20.67-26.42 \%$.

On average, the highest prenatal EPDS-3A score was higher in those with a history of anxiety disorders $(n=58$, $M=4.37, \mathrm{SD}=2.47)$ than in those without a history $(n=415$, $M=2.57, \mathrm{SD}=1.93), W=6861, p<0.001$, vd.a $=0.285$ (medium effect size). This was also evident in the postnatal sample, with higher EPDS-3A scores in those with a history of anxiety disorders $(n=51, M=3.25, \mathrm{SD}=2.29)$ than those without a history $(n=589, M=2.68, \mathrm{SD}=1.95)$, but the difference was not statistically significant, $W=12,856, p=0.087$, vd.a $=0.429$ (negligible effect size) (Fig. 2) (Supplement). 


\section{Discussion}

This study represents an exploration of the 3-factor model of the EPDS as administered prenatally and postnatally, in samples including both community and high-risk populations. We found that the 3-factor structure model of the EPDS (anhedonia, anxiety, and depression) was consistent across populations and was similar to that reported in previous studies (Tuohy and McVey 2008; Kubota et al. 2014; Lau et al. 2010). The EPDS-3A consistently emerged as a separate factor and was associated with a prenatal maternal history of anxiety disorders. These findings are important for several reasons.

Firstly, it has been argued that it is important to examine the utility of screening questionnaires in different populations of women at risk of postnatal depression (Austin et al. 2014). A strength of this study was the ability to examine the factor structure of the EPDS at different timepoints (i.e. prenatally and postnatally) and in different prenatal populations (i.e. high risk and community). It is important to note that the difference in setting (i.e. online versus clinical environment) may influence results, as the relative anonymity offered by the online environment could increase participants' willingness to more accurately disclose sensitive information (Bowling 2005). While our samples did include mothers of infants born prematurely and a small number of adolescent mothers, further research is required to better understand the factor structure of the EPDS in different (at risk) groups as well as different settings.

Secondly, the current study used both polychoric and Pearson correlation matrices for EFA, in addition to WLS and MLE methods for CFA. This rigorous application of different methodologies increased confidence that the 3-factor model of the EPDS is a genuine construct, rather than the result of idiosyncratic methodological choices.

Thirdly, between 1.9 and $26.4 \%$ of the women who had screened positive for anxiety symptoms using the EPDS$3 \mathrm{~A}$ had scored below threshold when using EPDS total score. This percentage was markedly influenced by the applied cut-offs, and the discrepancies highlight the urgent need for consistent validated cut-offs used across research and clinical settings. Given the inconsistencies associated with the EPDS and EPDS-3A, it may be preferable to use validated measures that screen for a variety of mood and anxiety disorders (e.g. the Matthey Generic Mood Questionnaire, Matthey et al. 2019). However, pending further validation studies, the EPDS-3A may be a useful adjunct to our current screening practice and facilitate patientprovider communication about anxiety symptoms, without further increasing the burden on women. This is of particular importance in contexts where no validated anxiety questionnaire is routinely administered in the perinatal period. It is important to note that the EPDS only asks about the last 7 days. A substantial proportion of high scores on the EPDS will reflect only transient symptoms of depression and/or anxiety (Agostini et al. 2019; Matthey and Ross-Hamid 2012).

Fourthly, our study was strengthened by the availability of data on maternal history of psychiatric disorders. This led to the finding of an association between prenatal EPDS-3A and maternal history of anxiety disorders. It remains unclear why postnatal EPDS-3A was unrelated to history of anxiety but this may be due to the postnatal sample consisting largely of women in the very early postnatal period (neonate postmenstrual age $=40.00 \pm 3.64$ weeks), when anxiety may be more related to specific experiences during labour (Bell and Andersson 2016, Paul et al. 2013). Further research is required in order to determine whether the EPDS-3A is uniquely associated with a history of anxiety disorders relative to other mental health concerns (Supplement). A major limitation of our study is the lack of validated measures of current anxiety symptoms. We recommend that future research includes comprehensive diagnostic interviews and clinical assessments of mental health and psychiatric history, as well as quantitative screening measures of anxiety.

Finally, it is important to note that although the overall factor structure was relatively stable, the exact factor loadings were influenced by analysis choices. Further studies are required to determine the measurement invariance (Widaman 2010) of this instrument.

We believe that studies may also benefit from analysing the relationship between EPDS-3A (or other screening tools) and physiological correlates of anxiety. For example, we are currently exploring the correlation between EPDS-3A score, maternal heart rate variability and neonatal brain development, using data collected from the wider $\mathrm{dHCP}$ project. It is hoped that this will enable us to better clarify the clinical relevance of a prenatal maternal EPDS-3A score, and ultimately to better target interventions with positive effects on early brain development.

Supplementary Information The online version contains supplementary material available at https://doi.org/10.1007/s00737-021-01153-0.

Acknowledgements We would like to acknowledge the contributions of our participants and their families; without whom, this work would not have been possible. We thank the nurses and midwives involved in data collection, the wider Developing Human Connectome team and the CRIS team at the NIHR Maudsley Biomedical Research Centre. We would also like to thank Professor Fruhling Rijsdijk and Dr Giorgia Michelini for valuable advice.

Authors' contributions The authors contributed to the article as follows: conceptualisation (AL, SV, SJC, ADE, MCC), funding acquisition (ADE), data collection (AL), data curation and analysis (AL, 
ALZ), supervision and project administration (SV, SJC, ADE, MCC), writing original draft (AL, ALZ), review and editing (AL, SV, ALZ, SJC, ADE, MCC). All authors approved of the final version of the article prior to submission.

Funding This work received funding from the European Research Council under the European Union's Seventh Framework Programme (FP7/20072013/ECR grant agreement no [319456] dHCP project) and the Medical Research Council [grant number MR/N013700].

This paper represents independent research partly funded by the National Institute for Health Research (NIHR) Biomedical Research Centre at South London and Maudsley NHS Foundation Trust and King's College London. This work was supported by core funding from the Wellcome/EPSRC Centre for Medical Engineering [WT203148/ $\mathrm{Z} / 16 / \mathrm{Z}]$. The views expressed are those of the author(s) and not necessarily those of the MRC, the NHS, the NIHR or the Department of Health and Social Care. The funders had no involvement in the collection, analysis or interpretation of data, in the writing of the report, or in the decision to submit the article for publication

Data availability We are unable to make the data openly available due to ethical constraints.

Code availability Code availability is available in the Supplementary Information.

\section{Declarations}

Ethics approval Ethical approval was obtained from the Riverside NHS Research Ethics Committee (14/LO/1169 and 18/LO/0786).

Consent to participate All participants provided written consent.

Consent for publication All co-authors have seen the manuscript and agree with the content, the ICMJE requirements for authorship have been met and each author believes that the manuscript represents honest work.

Conflicts of interest The authors declare no competing interests.

Open Access This article is licensed under a Creative Commons Attribution 4.0 International License, which permits use, sharing, adaptation, distribution and reproduction in any medium or format, as long as you give appropriate credit to the original author(s) and the source, provide a link to the Creative Commons licence, and indicate if changes were made. The images or other third party material in this article are included in the article's Creative Commons licence, unless indicated otherwise in a credit line to the material. If material is not included in the article's Creative Commons licence and your intended use is not permitted by statutory regulation or exceeds the permitted use, you will need to obtain permission directly from the copyright holder. To view a copy of this licence, visit http://creativecommons.org/licenses/by/4.0/.

\section{References}

Adhikari K, Patten SB, Williamson T, Patel AB, Premji S, Tough S, ... Metcalfe A (2020) Assessment of anxiety during pregnancy: are existing multiple anxiety scales suitable and comparable in measuring anxiety during pregnancy? J Psychosom Obstet Gynecol 1-7 https://doi.org/10.1080/0167482X.2020.1725462
Adouard F, Glangeaud-Freudenthal NMC, Golse B (2005) Validation of the Edinburgh postnatal depression scale (EPDS) in a sample of women with high-risk pregnancies in France. Arch Women's Ment Health 8(2):89-95. https://doi.org/10.1007/s00737-005-0077-9

Agampodi SB, Agampodi TC (2013) Antenatal depression in Anuradhapura, Sri Lanka and the factor structure of the Sinhalese version of Edinburgh Post Partum Depression Scale among pregnant women. PLoS ONE 8:e69708. https://doi.org/10.1371/journal.pone.0069708

Agostini F, Matthey S, Minelli M, Dellabartola S, Bonapace S (2019) Transient vs enduring distress in late pregnancy using the EPDS: a brief longitudinal exploratory study. J Reprod Infant Psychol 37(5):513-526

Albuquerque MR, Corrêa H, Santos W, Romano-Silva MA, Santos LMP (2017) A proposal for a new Brazilian six-item version of the Edinburgh Postnatal Depression Scale. Trends in Psychiatry and Psychotherapy 39(1):29-33. https://doi.org/10.1590/ 2237-6089-2016-0056

Allen M, Poggiali D, Whitaker K, Marshall TR, \& Kievit RA (2019) Raincloud plots: a multi-platform tool for robust data visualization. Wellcome Open Research 4. https://doi.org/10.12688/wellc omeopenres.15191.1

American College of Obstetricians and Gynecologists (2018) Screening for perinatal depression. ACOG Committee Opinion No. 757. Obstet Gynecol 132:e208-e212

Austin M-P, Highet N and the Expert Working Group (2017) Mental health care in the perinatal period: australian clinical practice guideline. Melbourne: Centre of Perinatal Excellence.

Austin MP, \& Marcé Society Position Statement Advisory Committee (2014) Marcé International Society position statement on psychosocial assessment and depression screening in perinatal women. Best Pract Res Clin Obstet Gynaecol 28(1):179-187. https://doi.org/10.1016/j.bpobgyn.2013.08.016

Baglin J (2014) Improving your exploratory factor analysis for ordinal data: a demonstration using FACTOR. Pract Assess Res Eval 19(5):2. https://doi.org/10.7275/dsep-4220

Bell AF, Andersson E (2016) The birth experience and women's postnatal depression: a systematic review. Midwifery 39:112123. https://doi.org/10.1016/j.midw.2016.04.014

Bentler PM (1990) Comparative fit indexes in structural models. Psychol Bull 107(2):238. https://doi.org/10.1037/0033-2909. 107.2.238

Bina R, Harrington D (2016) The Edinburgh Postnatal Depression Scale: screening tool for postpartum anxiety as well? Findings from a confirmatory factor analysis of the Hebrew version. Matern Child Health J 20(4):904-914. https://doi.org/10.1007/ s10995-015-1879-7

Bowling A (2005) Mode of questionnaire administration can have serious effects on data quality. J Public Health 27(3):281-291

Brouwers EP, van Baar AL, Pop VJ (2001) Does the Edinburgh postnatal depression scale measure anxiety? J Psychosom Res 51(5):659-663. https://doi.org/10.1016/S0022-3999(01) 00245-8

Chabrol H, Teissedre F (2004) Relation between Edinburgh Postnatal Depression Scale scores at 2-3 days and 4-6 weeks postpartum. J Reprod Infant Psychol 22(1):33-39. https://doi.org/10.1080/02646 830310001643067

Chiu YHM, Sheffield PE, Hsu HHL, Goldstein J, Curtin PC, Wright RJ (2017) Subconstructs of the Edinburgh Postnatal Depression Scale in a multi-ethnic inner-city population in the US. Arch Women's Ment Health 20(6):803-810. https://doi.org/10.1007/ s00737-017-0765-2

Coates R, Ayers S, de Visser R (2017) Factor structure of the Edinburgh Postnatal Depression Scale in a population-based sample. Psychol Assess 29(8):1016. https://doi.org/10.1037/pas00 00397 
Cox JL, Holden JM, Sagovsky R (1987) Detection of postnatal depression. Development of the 10-item Edinburgh Postnatal Depression Scale. Br J Psychiatry 150:782-786. https://doi.org/10.1192/BJP. 150.6.782

Cunningham NK, Brown PM, Page AC (2015) Does the Edinburgh Postnatal Depression Scale measure the same constructs across time? Arch Womens Ment Health 18:793-804. https://doi.org/10. 1007/s00737-014-0485-9

Dziuban CD, Shirkey EC (1974) When is a correlation matrix appropriate for factor analysis? Some Decision Rules Psychological Bulletin 81(6):358. https://doi.org/10.1037/h0036316

Field T (2018) Postnatal anxiety prevalence, predictors and effects on development: a narrative review. Infant Behav Dev 51:24-32. https://doi.org/10.1016/j.infbeh.2018.02.005

Flom JD, Chiu YHM, Tamayo-Ortiz M, Schnaas L, Curtin PC, Wright RJ, ...Rosa MJ 2018 Subconstructs of the Edinburgh Postpartum Depression Scale in a postpartum sample in Mexico City J Affect Disord 238142146 https://doi.org/10.1016/j.jad. 2018.05.049.

Gutierrez-Zotes A,Gallardo-Pujol D, Labad J, Martín Santos R, GarcíaEsteve L, Gelabert E, ...Canellas F 2018 Factor structure of the Spanish version of the Edinburgh postnatal depression scale Actas Espanolas De Psiquiatria 465174182

Hartley CM, Barroso N, Rey Y, Pettit JW, Bagner DM (2014) Factor structure and psychometric properties of English and Spanish versions of the Edinburgh Postnatal Depression Scale among Hispanic women in a primary care setting. J Clin Psychol 70:1240 1250. https://doi.org/10.1002/jclp.22101

Hayes AF, \& Coutts JJ (2020) Use omega rather than Cronbach's alpha for estimating reliability. But.... Communication Methods and Measures, 14(1), 1-24. https://doi.org/10.1080/19312458.2020.1718629

Holgado-Tello FP, Chacón-Moscoso S, Barbero-García I, Vila-Abad E (2010) Polychoric versus Pearson correlations in exploratory and confirmatory factor analysis of ordinal variables. Qual Quant 44(1):153. https://doi.org/10.1007/s11135-008-9190-y

Howard MC (2016) A review of exploratory factor analysis decisions and overview of current practices: what we are doing and how can we improve? Int J Hum Comput Interact 32(1):51-62. https://doi. org/10.1080/10447318.2015.1087664

Howard LM, Khalifeh H (2020) Perinatal mental health: a review of progress and challenges. World Psychiatry 19(3):313-327. https:// doi.org/10.1002/wps.20769

Hu LT, Bentler PM (1999) Cutoff criteria for fit indexes in covariance structure analysis: conventional criteria versus new alternatives. Struct Equ Modeling 6(1):1-55. https://doi.org/10.1080/10705 519909540118

Jackson DL, Gillaspy JA Jr, Purc-Stephenson R (2009) Reporting practices in confirmatory factor analysis: an overview and some recommendations. Psychol Methods 14(1):6. https://doi.org/10. 1037/a0014694

Jomeen J, Martin CR (2005) Confirmation of an occluded anxiety component within the Edinburgh Postnatal Depression Scale (EPDS) during early pregnancy. J Reprod Infant Psychol 23:143-154. https://doi.org/10.1080/02646830500129297

Jomeen J, Martin CR (2007) Replicability and stability of the multidimensional model of the Edinburgh Postnatal Depression Scale in late pregnancy. J Psychiatr Ment Health Nurs 14, 319-324. https:// doi.org/10.1111/j.1365-2850.2007.01084.x

King PAL (2012) Replicability of structural models of the Edinburgh Postnatal Depression Scale (EPDS) in a community sample of postpartum African American women with low socioeconomic status. Arch Womens Ment Health 15(2):77-86. https://doi.org/ 10.1007/s00737-012-0260-8

Kozinszky Z, Dudas RB (2015) Validation studies of the Edinburgh Postnatal Depression Scale for the antenatal period. J Affect Disord 176:95-105. https://doi.org/10.1016/j.jad.2015.01.044
Kroenke K (2020) Two birds with one stone: joint screening for perinatal depression and anxiety. J Womens Health. https://doi.org/ 10.1089/jwh.2020.8643

C Kubota T Okada B Aleksic Y Nakamura S Kunimoto M Morikawa ...T Morita 2014 Factor structure of the Japanese version of the Edinburgh Postnatal Depression Scale in the postpartum period PLoS ONE 98 e103941 https://doi.org/10.1371/journal.pone. 0103941

C Kubota T Inada Y Nakamura T Shiino M Ando B Aleksic ....M Sato 2018 Stable factor structure of the Edinburgh Postnatal Depression Scale during the whole peripartum period: results from a Japanese prospective cohort study Sci Rep 8117659 https://doi.org/10.1038/ s41598-018-36101-z

Kwan R, Bautista D, Choo R, Shirong C, Chee C, Mei Saw S, Chong YS, Kwek K, Meaney MJ, Rush AJ, Chen H (2015) The Edinburgh Postnatal Depression Scale as a measure for antenatal dysphoria. J Reprod Infant Psychol 33:28-41. https://doi.org/10.1080/ 02646838.2014.949642

Lau Y, Wang Y, Yin L, Chan KS, Guo X (2010) Validation of the Mainland Chinese version of the Edinburgh Postnatal Depression Scale in Chengdu mothers. Int J Nurs Stud 47, 1139-1151. https://doi.org/10.1016/j.ijnurstu.2010.02.005

A Lautarescu MC Craig V Glover 2020 Prenatal stress: effects on fetal and child brain development stress and brain health: across the Life Course 17 https://doi.org/10.1016/bs.irn.2019.11.002

Leach LS, Poyser C, Fairweather-Schmidt K (2017) Maternal perinatal anxiety: a review of prevalence and correlates. Clin Psychol 21(1):4-19. https://doi.org/10.1111/cp.12058

Letourneau NL, Dennis CL, Cosic N, Linder J (2017) Theeffect of perinatal depression treatment for mothers on parenting and child development: a systematic review. Depress Anxiety 34(10):928-966. https://doi.org/10.1002/da.22687

B Levis Z Negeri Y Sun A Benedetti BD Thombs 2020 Accuracy of the Edinburgh Postnatal Depression Scale (EPDS) for screening to detect major depression among pregnant and postpartum women: systematic review and meta-analysis of individual participant data BMJ $371 \mathrm{https}: / /$ doi.org/10.1136/bmj.m4022

Loyal D, Sutter AL, Rascle N (2020) Screening Beyond Postpartum Depression: Occluded Anxiety Component in the EPDS (EPDS3A) in French Mothers. Matern Child Health J 24(3):369-377. https://doi.org/10.1007/s10995-020-02885-8

Lydsdottir LB, Howard LM, Olafsdottir H, Thome M, Tyrfingsson P, \& Sigurdsson JF (2019) The psychometric properties of the Icelandic version of the Edinburgh Postnatal Depression Scale (EPDS) when used prenatal. Midwifery 69, 45-51. https://doi. org/10.1016/j.midw.2018.10.009.

Maroto-Navarro G, Garcia-Calvente MM, Fernandez-Parra A (2005) Evaluation of mood in the postpartum period with the Edinburgh Postnatal Depression Scale. Int J Clin Health Psychol 5(2):305-318

Martin CR, Thompson DR (1999) Utility of the Hospital Anxiety and Depression Scale in patients with end-stage renal disease on continuous ambulatory peritoneal dialysis. Psychol Health Med 4(4):369-376. https://doi.org/10.1080/135485099106117

Martin CR, Thompson DR (2000) A psychometric evaluation of the Hospital Anxiety and Depression Scale in coronary care patients following acute myocardial infarction. Psychol Health Med 5(2):193-201. https://doi.org/10.1080/713690189

Martin CR, Tweed AE, Metcalfe MS (2004) A psychometric evaluation of the hospital anxiety and depression scale in patients diagnosed with end-stage renal disease. Br J Clin Psychol 43(1):51-64. https://doi.org/10.1348/014466504772812968

Martin CR, Redshaw M (2018) Establishing a coherent and replicable measurement model of the Edinburgh postnatal depression scale. Psychiatry Res 264:182-191. https://doi.org/10.1016/j. psychres.2018.03.062 
Matthey S (2008) Using the Edinburgh Postnatal Depression Scale to screen for anxiety disorders. depress Anxiety 25:926-931. https://doi.org/10.1002/da.20415

Matthey S, Ross-Hamid C (2012) Repeat testing on the Edinburgh Depression Scale and the HADS-A in pregnancy: differentiating between transient and enduring distress. J Affect Disord 141(2-3):213-221

Matthey S, Fisher J, Rowe H (2013) Using the Edinburgh Postnatal Depression Scale to screen for anxiety disorders: conceptual and methodological considerations. J Affect Disord 146:224-230. https://doi.org/10.1016/j.jad.2012.09.009

Matthey S, Agostini F (2017) Using the Edinburgh Postnatal Depression Scale for women and men-some cautionary thoughts. Arch Womens Ment Health 20(2):345-354. https://doi.org/10. 1007/s00737-016-0710-9

Matthey S, Souter K, Valenti B, Ross-Hamid C (2019) Validation of the MGMQ in screening for emotional difficulties in women during pregnancy. J Affect Disord 256:156-163. https://doi.org/ 10.1016/j.jad.2019.05.037

Mazhari S, Nakhaee N (2007) Validation of the Edinburgh Postnatal Depression Scale in an Iranian sample. Archives of Womens Mental Health 10:293-297. https://doi.org/10.1007/ s00737-007-0204-x

McNeish D (2017) Exploratory factor analysis with small samples and missing data. J Pers Assess 99(6):637-652. https://doi.org/ $10.1080 / 00223891.2016 .1252382$

Milgrom J, \& Gemmill AW (eds) (2015) Identifying perinatal depression and anxiety: evidence-based practice in screening, psychosocial assessment and management. John Wiley \& Sons. https://doi.org/10.1002/9781118509722

Montazeri A, Torkan B, Omidvari S (2007) The Edinburgh Postnatal Depression Scale (EPDS): translation and validation study of the Iranian version. BMC Psychiatry 7(1):11. https://doi.org/ 10.1186/1471-244X-7-11

Muzik M, Klier CM, Rosenblum KL, Holzinger A, Umek W, Katschnig H (2000) Are commonly used self-report inventories suitable for screening postpartum depression and anxiety disorders? Acta Psychiatr Scand 102(1):71-73. https://doi.org/ 10.1034/j.1600-0447.2000.102001071.x

National Institute for Health and Care Excellence (2014) Antenatal and postnatal mental health: clinical management and service guidance. Clinical Guidance [CG192].

National Childbirth Trust (2017) The hidden half: bringing postnatal mental illness out of hiding. https://www.nct.org.uk/sites/defau 1t/files/related_documents/NCT\%20The $\% 20$ Hidden $\% 20 \mathrm{Half} \%$ 20shortform.pdf

Norhayati MN, Hazlina NN, Asrenee AR, Emilin WW (2015) Magnitude and risk factors for postpartum symptoms: a literature review. J Affect Disord 175:34-52. https://doi.org/10.1016/j. jad.2014.12.041

O’Donnell KJ, Glover V, Lahti J, Lahti M, Edgar RD, Räikkönen K, \& O'Connor TG (2017) Maternal prenatal anxiety and child COMT genotype predict working memory and symptoms of ADHD. PloS one 12(6). https://doi.org/10.1371/journal.pone. 0177506

Paul IM, Downs DS, Schaefer EW, Beiler JS, Weisman CS (2013) Postpartum anxiety and maternal-infant health outcomes. Pediatrics 131(4):e1218-e1224. https://doi.org/10.1542/peds. 2012-2147

Phillips J, Charles M, Sharpe L, Matthey S (2009) Validation of the subscales of the Edinburgh Postnatal Depression Scale in a sample of women with unsettled infants. J Affect Disord 118:101-112. https:// doi.org/10.1016/j.jad.2009.02.004

Phua DY, Kee MK, Koh DX, Rifkin-Graboi A, Daniels M, Chen H, ... \& Meaney MJ (2017) Positive maternal mental health during pregnancy associated with specific forms of adaptive development in early childhood: evidence from a longitudinal study. Development and Psychopathology 29(5), 1573-1587. https://doi.org/10. 1017/S0954579417001249

Pop VJ, Komproe IH, Van Son MJ (1992) Characteristics of the Edinburgh post natal depression scale in The Netherlands. J Affect Disord 26(2):105-110. https://doi.org/10.1016/0165-0327(92) 90041-4

R Core Team (2018) R: A language and environment for statistical computing. R Foundation for Statistical Computing, Vienna, Austria. URL https://www.R-project.org/.

Raykov T (2004) Behavioral scale reliability and measurement invariance evaluation using latent variable modeling. Behav Ther 35(2):299 331. https://doi.org/10.1016/S0005-7894(04)80041-8

Ross LE, Evans SG, Sellers EM, Romach MK (2003) Measurement issues in postpartum depression part 1: anxiety as a feature of postpartum depression. Arch Womens Ment Health 6(1):51-57. https://doi.org/10.1007/s00737-002-0155-1

Schumacker RE, Lomax RG (2010) A beginner's guide to structural equation modeling, 3rd edn. Routledge/Taylor \& Francis Group. https://doi.org/10.4324/9780203851319

Scottish Intercollegiate Guidelines Network (SIGN) (2012) Management of perinatal mood disorders. Edinburgh: SIGN.

Shapiro A, Ten Berge JM (2002) Statistical inference of minimum rank factor analysis. Psychometrika 67(1):79-94. https://doi.org/ 10.1007/BF02294710

Smith-Nielsen J, Matthey S, Lange T, Væver MS (2018) Validation of the Edinburgh Postnatal Depression Scale against both DSM-5 and ICD-10 diagnostic criteria for depression. BMC Psychiatry 18(1):1-12

Stasik-O'Brien SM, McCabe-Beane JE, Segre LS (2019) Using the EPDS to identify anxiety in mothers of infants on the neonatal intensive care unit. Clin Nurs Res 28(4):473-487. https://doi.org/ $10.1177 / 1054773817740532$

Streiner DL (1994) Figuring out factors: the use and misuse of factor analysis. Can J Psychiatry 39(3):135-140. https://doi.org/10.3138/ 9781442662827-012

Sudhanthar S, Thakur K (2019) Postpartum depression screening: are we doing a competent job? BMJ Open Quality 8(4):e000616. https://doi.org/10.1136/bmjoq-2018-000616

Swalm D, Brooks J, Doherty D, Nathan E, Jacques A (2010) Using the Edinburgh Postnatal Depression Scale to screen for perinatal anxiety. Arch Womens Ment Health 13:515-522. https://doi.org/10.1007/s00737-010-0170-6

Töreki A, Andó B, Keresztúri A, Sikovanyecz J, Dudas RB, Janka Z, Kozinszky Z, Pál A (2013) The Edinburgh Postnatal Depression Scale: translation and antepartum validation for a Hungarian sample. Midwifery 29:308-315. https://doi.org/10.1016/j.midw. 2012.01.011

Tucker LR, Lewis C (1973) A reliability coefficient for maximum likelihood factor analysis. Psychometrika 38(1):1-10. https://doi.org/ 10.1007/BF02291170

Tuohy A, McVey C (2008) Subscales measuring symptoms of non-specific depression, anhedonia, and anxiety in the Edinburgh Postnatal Depression Scale. Br J Clin Psychol 47:153-169. https://doi.org/10. 1111/j.2044-8260.2008.tb00463.x

van der Zee-van den Berg AI, Boere-Boonekamp MM, Groothuis-Oudshoorn CG, \& Reijneveld SA (2019) The Edinburgh Postpartum Depression Scale: stable structure but subscale of limited value to detect anxiety. PloS one 14(9), e0221894. https://doi.org/10. 1371/journal.pone.0221894

Vargha A, Delaney HD (2000) A critique and improvement of the CL common language effect size statistics of McGraw and Wong. Journal of Educational and Behavioral Statistics 25(2):101-132

Vázquez MB, Míguez MC (2019) Validation of the Edinburgh postnatal depression scale as a screening tool for depression in Spanish pregnant women. J Affect Disord 246:515-521. https://doi.org/ 10.1016/j.jad.2018.12.075 
Vivilaki VG, Dafermos V, Kogevinas M, Bitsios P, Lionis C (2009) The Edinburgh Postnatal Depression Scale: translation and validation for a Greek sample. BMC Public Health 9, 329. https://doi.org/ 10.1186/1471-2458-9-329

Watkins MW (2018) Exploratory factor analysis: a guide to best practice. J Black Psychol 44(3):219-246. https://doi.org/10.1177/ 0095798418771807

Widaman KF, Ferrer d E, \& Conger RD, (2010) Factorial invariance within longitudinal structural equation models: measuring the same construct across time. Child Dev Perspect 4(1):10-18. https://doi.org/10.1111/j. 1750-8606.2009.00110.x
Wothke W (1993) Nonpositive definite matrices in structural modeling. In: Bollen KA, Long JS (eds) Testing structural equation models. Sage, Newbury Park, pp 256-293

Q Zhong B Gelaye M Rondon SE Sánchez PJ García E Sánchez ... MA Williams 2014 Comparative performance of patient health questionnaire-9 and Edinburgh Postnatal Depression Scale for screening antepartum depression J Affect Disord $16217 \mathrm{https} / / /$ doi.org/10.1016/j.jad.2014.03.028

Publisher's note Springer Nature remains neutral with regard to jurisdictional claims in published maps and institutional affiliations. 